\title{
First-Line Support by Intra-Aortic Balloon Pump in Non-Ischaemic Cardiogenic Shock in the Era of Modern Ventricular Assist Devices
}

\author{
Corstiaan A. den Uila, b Giorgia Galli ${ }^{a} \quad$ Lucia S. Jewbalia, b Kadir Caliskan ${ }^{a}$ \\ Olivier C. Manintveld ${ }^{a}$ Jasper J. Brugts ${ }^{a}$ Nicolas M. van Mieghem ${ }^{a}$ \\ Mattie J. Lenzen ${ }^{a}$ Eric Boersma ${ }^{a}$ Alina A. Constantinescu ${ }^{a}$ \\ a Thoraxcenter, Department of Cardiology, and b Department of Intensive Care Medicine, Erasmus Medical Center, \\ Rotterdam, The Netherlands
}

\section{Keywords}

Cardiogenic shock · Cardiomyopathy $\cdot$ End-stage heart failure $\cdot$ Intra-aortic balloon pump $\cdot$ Mechanical circulatory support

\section{Abstract}

Objectives: Little is known about circulatory support in cardiogenic shock (CS) from other causes than the acute coronary syndrome or after cardiotomy. We evaluated the effects of first-line intra-aortic balloon pump (IABP) support in this subpopulation of CS patients. Methods: A retrospective study was performed in 27 patients with CS from end-stage cardiomyopathy supported firstly by IABP in the years 20112016. Results: At $24 \mathrm{~h}$, lactate decreased from 3.2 (2.1-6.8) to $1.8(1.2-2.2) \mathrm{mmol} / \mathrm{L}(p<0.001)$. Eighteen patients $(67 \%)$ defined as IABP responders were successfully bridged to either recovery $(n=7)$, left ventricular assist device $(n=5)$, or heart transplantation $(n=6)$. IABP failed in 9 patients (non-responders, 33\%) who either died ( $n=7$ ) or needed support by extracorporeal membrane oxygenation $(n=2)$. At $24 \mathrm{~h}$ of IABP support, urinary output was higher $(2,660$ [1,835-4,440] vs. $1,200[649-2,385] \mathrm{mL} ; p=0.02)$ and fluid balance more negative $(-1,564[-2,673$ to $-1,086]$ vs. -500 [-930 to +240$]$ $\mathrm{mL} ; p<0.001)$ in responders than non-responders. Overall

\begin{tabular}{ll}
\hline KARGER & $\begin{array}{l}\text { ( ) } 2017 \text { The Author(s) } \\
\text { Published by S. Karger AG, Basel }\end{array}$ \\
$\begin{array}{l}\text { E-Mail karger@karger.com } \\
\text { www.karger.com/crd }\end{array}$ & $\begin{array}{l}\text { Karger } \\
\text { This article is licensed under the Creative Commons Attribution- } \\
\text { NonCommercial-NoDerivatives 4.0 International License (CC BY- } \\
\text { NC-ND) (http://www.karger.com/Services/OpenAccessLicense). } \\
\text { Usage and distribution for commercial purposes as well as any dis- } \\
\text { tribution of modified material requires written permission. }\end{array}$
\end{tabular}

survival at 1 year was 63\%. Conclusion: In most patients, first-line support by IABP in end-stage cardiomyopathy is associated with improvement in organ perfusion and clinical stabilisation for at least $24 \mathrm{~h}$ allowing time for decision making on next therapies.

\footnotetext{
(c) 2017 The Author(s)

Published by S. Karger AG, Basel
}

\section{Introduction}

Mechanical circulatory support may be necessary to prevent irreversible end-organ damage in cardiogenic shock (CS) [1, 2]. For more than 40 years, the intra-aortic balloon pump (IABP) has been used in CS to improve coronary and peripheral perfusion via diastolic balloon inflation and to augment left ventricular (LV) performance via systolic balloon deflation through a decreased afterload $[3,4]$. The IABP is safe and minimally invasive, but its effectiveness has been questioned and, according to the 2016 European Society of Cardiology guidelines, is not routinely recommended for CS support [2]. IABP did not improve short- and long-term survival in the setting of CS complicating acute myocardial infarction (AMI), as reported in the IABP-SHOCK II trial $[5,6]$. Nowadays, advanced mechanical support capable to provide greater

Corstiaan A. den Uil, MD, PhD

Erasmus Medical Center

's-Gravendijkwal 230

NL-3015 CE Rotterdam (The Netherlands)

E-Mail c.denuil@erasmusmc.nl 


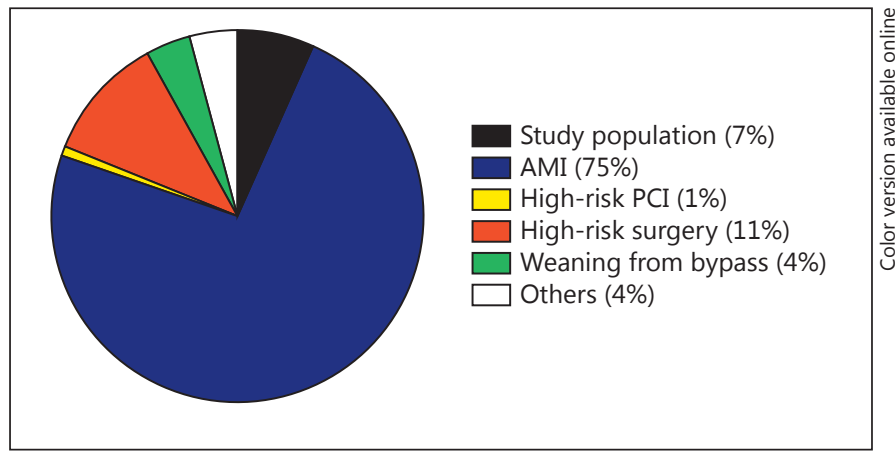

Fig. 1. Distribution of indications for intra-aortic balloon pump in our Centre. AMI, acute myocardial infarction; PCI, percutaneous coronary intervention.

output is available, either as percutaneous ventricular assist device ( $\mathrm{pVAD}$ ) or as extracorporeal membrane oxygenation (ECMO) [2]. However, these systems are more invasive and not available outside tertiary care centres. Although the most frequent cause of CS is acute coronary syndrome, non-ischaemic aetiology accounts for up to one-fifth of CS cases [7]. The haemodynamic needs may be different in non-ischaemic CS, where low output may be triggered by volume overload, versus AMI, where myocardial contractile reserve is acutely impaired. Therefore, in non-ischaemic CS, we aimed to investigate the effect of first-line support by IABP on haemodynamic stabilisation and selection in subsequent therapies.

\section{Patients and Methods}

\section{Study Population}

We reviewed the data of all patients supported by IABP at the Erasmus Medical Centre (MC), Rotterdam, the Netherlands, between March 2011 and November 2016. Patients were included in the analysis when the indication for IABP was inotropy-dependent heart failure with signs of hypoperfusion and tissue hypoxia (e.g., blood lactate levels $>2 \mathrm{mmol} / \mathrm{L}$, urinary output $<30 \mathrm{~mL} / \mathrm{h}$ during at least $4 \mathrm{~h}$, cold extremities, and altered mental state). Criteria for exclusion were: (1) AMI in the previous 30 days; (2) cardiac surgery in the previous 30 days; (3) ECMO as first mechanical circulatory support; and (4) IABP inserted as support for high-risk coronary intervention or cardiac surgery. Among 411 patients supported by IABP in the Erasmus MC, there were 27 patients (7\%) in whom IABP was inserted for refractory heart failure deteriorating following CS not caused by acute coronary syndrome or cardiac surgery (Fig. 1).

\section{Ethics}

This retrospective study was conducted according to the privacy policy of the Erasmus MC and according to the Erasmus MC regulations for the appropriate use of data in patient-oriented research.

\section{IABP Support}

A Maquet/Datascope fibre-optic IAB (Hilversum, The Netherlands) was inserted by catheterisation of the right or left common femoral artery using the Seldinger technique either at bedside or under fluoroscopic guidance. After insertion, unfractionated heparin was administered intravenously according to our institution protocol, aiming to achieve an activated partial thromboplastin time between 60 and $80 \mathrm{~s}$. The indication for continuation of IABP treatment, weaning, or escalation to other mechanical circulatory support was evaluated daily by a multidisciplinary team involving an intensive care specialist, a heart failure cardiologist, and a cardiothoracic surgeon. In all patients, candidacy for an LV assist device (LVAD) or heart transplantation was evaluated. For the patients already listed for heart transplantation, urgency was requested when IABP support became necessary in patients not suitable for LVAD. We defined the success of IABP support as haemodynamic improvement allowing titration of heart failure medication and weaning from IABP or haemodynamic stabilisation until LVAD or heart transplantation (IABP responders). Failure of IABP support was defined as death during support, escalation of temporary mechanical support to ECMO, or IABP removal due persistent multi-organ failure and contraindications for LVAD or transplantation (IABP non-responders).

\section{Data Collection}

Data were retrieved from patient medical records and the local hospital database. Standard demographic data and medication were recorded at baseline. Patients meeting criteria for LV failure (LV ejection fraction $<35 \%$ ) and right ventricular (RV) failure (tricuspid annular plane systolic excursion $<1.6 \mathrm{~cm}$, or qualitatively assessed moderate or severe RV systolic dysfunction together with at least moderate tricuspid regurgitation, and dilated inferior caval vein) were classified as biventricular heart failure. The clinical and laboratory parameters were collected at baseline and 24 and $48 \mathrm{~h}$ after IABP insertion from the local electronic hospital database. Systemic blood pressure was measured invasively with a radial arterial line. Patients were classified according to the profiles defined by the Interagency Registry for Mechanically Assisted Circulatory Support (INTERMACS), i.e., class 1 for life-threatening critical CS necessitating vasopressor support or class 2 for progressive decline in inotropic support [8]. In addition, the HeartMate II risk score, which included age, albumin, and creatinine levels, INR, and centre volume, was calculated $[8,9]$. Systemic vascular resistance was calculated as $80 \times$ (mean arterial pressure - right atrial pressure)/ cardiac output. Pulmonary artery pulsatility index was calculated as (systolic pulmonary artery pressure - diastolic pulmonary artery pressure)/right atrial pressure. RV stroke work index was calculated as stroke volume index $\times$ (mean pulmonary artery pressure - right atrial pressure $) \times 0.0136$. Estimated glomerular filtration rate was calculated from creatinine values using the CockcroftGault equation. Cumulative 24-h fluid balance was calculated as the difference between fluid intake and urinary output. Echocardiographic parameters were obtained from the local database. LV ejection fraction was estimated based on wall motion index. The degree of mitral regurgitation had been graded as absent, mild, moderate, or severe according to established echocardiography criteria. IABP-related bleeding, infectious and ischaemic complications, as well as the number of blood transfusions were registered. 
Table 1. Baseline characteristics of the study population

Total $(N=27) \quad$ IABP responders $(n=18)$ IABP non-responders $(n=9) p$ value

Demographic data

Age, years

Male gender

Body mass index

Cardiomyopathy (non-ischaemic etiology)

New-onset heart failure

Biventricular failure

INTERMACS profile 1

HeartMate II risk score

$\begin{array}{cc}50(46-59) & 50(44-59) \\ 16(59) & 8(44) \\ 24.2(21.5-25.4) & 24.9(21.5-26.0) \\ 21(78) & 15(83) \\ 5(19) & 4(22) \\ 16(59) & 11(61) \\ 24(89) & 16(89) \\ 4.8(3.4-8.3) & 5.3(3.7-12.4)\end{array}$

$\begin{aligned} 51 & (47-61) \\ 8 & (90) \\ 24.1 & (21.7-24.6) \\ & 6(67) \\ & 1(11) \\ & 5(56) \\ & 8(89) \\ 4.8 & (3.2-5.9)\end{aligned}$

ns

Haemodynamic parameters and treatment

Systolic blood pressure, $\mathrm{mm} \mathrm{Hg}$

Diastolic blood pressure, $\mathrm{mm} \mathrm{Hg}$

Mean arterial pressure, $\mathrm{mm} \mathrm{Hg}$

Heart rate, b.p.m.

Cardiac index ${ }^{\mathrm{a}}, \mathrm{L} / \mathrm{min} / \mathrm{m}^{2}$

Right atrial pressure, $\mathrm{mm} \mathrm{Hg}$

Mean pulmonary artery pressure ${ }^{\mathrm{a}}, \mathrm{mm} \mathrm{Hg}$

Pulmonary capillary wedge pressure ${ }^{\mathrm{a}}, \mathrm{mm} \mathrm{Hg}$

Systemic vascular resistance ${ }^{\mathrm{a}}$, dyn $\times \mathrm{s} / \mathrm{cm}^{5}$

Pulmonary artery pulsatility index ${ }^{\mathrm{a}}$

Right ventricular stroke work index ${ }^{\mathrm{a}}$

Right atrial pressure/wedge pressure ratio ${ }^{a}$

Central venous oxygen saturation, \%

Vasopressor (norepinephrine)

Inotropes (dobutamine or enoximone)

Norepinephrine, $\mu \mathrm{g} / \mathrm{kg} / \mathrm{min}$

Dobutamine, $\mu \mathrm{g} / \mathrm{kg} / \mathrm{min}$

Enoximone, $\mu \mathrm{g} / \mathrm{kg} / \mathrm{min}$

Renal replacement therapy before IABP

Mechanical ventilation before IABP

$\begin{array}{lc}90(80-92) & 90(80-94) \\ 55(49-60) & 56(47-60) \\ 67(60-71) & 66(59-74) \\ 90(80-107) & 95(80-106) \\ 2.0(1.6-2.1) & 1.9(1.6-2.1) \\ 20(17-21) & 20(15-20) \\ 31(23-38) & 28(23-36) \\ 22(14-25) & 23(14-26) \\ 972(694-1,113) & 972(663-1,101) \\ 1.2(0.5-1.4) & 0.8(0.4-1.2) \\ 3.6(1.1-5.1) & 2.8(0.8-4.6) \\ 0.9(0.7-1.4) & 0.8(0.7-1.9) \\ 46(34-61) & 54(45-67) \\ 19(70) & 13(72) \\ 22(82) & 14(78) \\ 0.2(0.1-0.3) & 0.2(0.1-0.3) \\ 5(3-7) & 4(2-7) \\ 1(1-2) & 1(1-1) \\ 2(7) & 1(6) \\ 6(22) & 4(22)\end{array}$

$\begin{array}{ll}89(81-95) & \text { ns } \\ 50(50-61) & \text { ns } \\ 68(59-71) & \text { ns }\end{array}$

$68(59-71)$

$89(80-117)$

$2.0(1.6-2.2)$

$20(19-27)$

$35(25-39)$

$21(15-24)$

$986(736-1,196)$

$1.4(1.2-1.5)$

$4.4(2.1-6.5)$

$1.0(0.8-1.2)$

$33(32-46)$

$6(67)$

8 (89)

$0.2(0.1-0.3)$

$6(3-7)$

$1(0.5-1)$

$1(11)$

2 (22)

0.04

ns

ns

ns

ns

ns

\section{Biochemistry}

Lactate, $\mathrm{mmol} / \mathrm{L}$

Haemoglobin, $\mathrm{mmol} / \mathrm{L}$

Bilirubin, $\mu \mathrm{mol} / \mathrm{L}$

Urea, $\mathrm{mmol} / \mathrm{L}$

Creatinine, $\mu \mathrm{mol} / \mathrm{L}$

eGFR, $\mathrm{mL} / \mathrm{min} / 1,73 \mathrm{~m}^{2}$

C-reactive protein, $\mathrm{mg} / \mathrm{L}$

Sodium, $\mathrm{mmol} / \mathrm{L}$

Potassium, mmol/L

NT-proBNP, pmol/L

Glutamic oxaloacetic transaminase, $\mathrm{U} / \mathrm{L}$

Glutamic pyruvic transaminase, U/L

$\begin{array}{cc}3.3(2.1-6.8) & 3.6(2.1-8.1) \\ 7.3(6.2-8.6) & 7.6(6.4-8.6) \\ 34(21-52) & 23(18-37) \\ 20(11-30) & 18(10-27) \\ 201(124-296) & 199(137-245) \\ 34(26-60) & 33(27-49) \\ 32(16-92) & 25(9-54) \\ 133(128-138) & 133(127-135) \\ 4.5(4.1-5.0) & 4.4(4.0-5.1) \\ 1,422(766-3,219) & 2,069(875-4,123) \\ 64(32-336) & 123(35-926) \\ 81(24-369) & 119(24-840)\end{array}$

$\begin{aligned} 3.2 & (2.3-5.5) \\ 6.5 & (5.9-7.5) \\ 45 & (34-102) \\ 30 & (20-42) \\ 246 & (95-355) \\ 34 & (21-87) \\ 55 & (33-152) \\ 134 & (129-140) \\ 4.7 & (4.6-5.2) \\ 1,094 & (255-1,856) \\ 45 & (30-282) \\ 78 & (22-253)\end{aligned}$

ns

ns

ns

ns

ns

ns

ns

ns

ns

ns

ns

ns

0.04

ns

ns

ns

ns

ns

ns

ns

Echocardiography

Left ventricular ejection fraction, \%

Left ventricular end-diastolic diameter, $\mathrm{mm}$

$\mathrm{E} / \mathrm{E}^{\prime}$ ratio

Mitral regurgitation (moderate or severe)

TAPSE, $\mathrm{cm}$

Tricuspid regurgitation (moderate or severe)

Diameter of the inferior cava, $\mathrm{cm}$

$\begin{array}{lc}20(15-25) & 22(19-26) \\ 63(56-71) & 62(56-68) \\ 18(13-26) & 17(12-27) \\ 17(63) & 12(67) \\ 1.3(1.3-1.5) & 1.3(1.2-1.5) \\ 9(33) & 5(28) \\ 2.4(2.2-2.6) & 2.4(2-2.5)\end{array}$

$$
\begin{gathered}
15(15-20) \\
63(55-75) \\
20(11-30) \\
5(56) \\
1.5(1.3-2.0) \\
4(44) \\
2.4(2.3-2.9)
\end{gathered}
$$

ns

0.03

0.02

ns

ns

0.01

ns

ns

ns

ns

ns

Ranges and percentages are given in parentheses. INTERMACS, Interagency Registry for Mechanically Assisted Circulatory Support; NT-proBNP, N-terminal pro-B-type natriuretic peptide; eGFR, estimated glomerular filtration rate; IABP, intra-aortic balloon pump; TAPSE, tricuspid annular plane systolic excursion. ${ }^{\text {a }}$ Data were available for 12/27 (44\%) patients.

IABP in End-Stage Cardiomyopathy

Cardiology 2017;138:1-8

DOI: $10.1159 / 000471846$

0.03

ns

ns

ns

ns

ns

ns

03
s
s
ns


Table 2. Changes in haemodynamics and markers of organ perfusion after intra-aortic balloon pump (IABP) insertion in the study patients

\begin{tabular}{|c|c|c|c|c|}
\hline & Before IABP & $24 \mathrm{~h}$ after IABP & $48 \mathrm{~h}$ after IABP & $p$ for trend \\
\hline Mean arterial pressure, $\mathrm{mm} \mathrm{Hg}$ & $67(60-71)$ & $75(68-82)^{*}$ & $74(63-81)^{*}$ & 0.01 \\
\hline Heart rate, b.p.m. & $90(80-107)$ & $88(79-99)$ & $85(75-99)$ & ns \\
\hline Central venous oxygen saturation, $\%$ & $46(34-61)$ & $62(51-75)^{*}$ & $57(49-64)^{*}$ & 0.001 \\
\hline Right atrial pressure, $\mathrm{mm} \mathrm{Hg}$ & $20(17-21)$ & $15(12-17)^{*}$ & $12(10-18)^{*}$ & $<0.001$ \\
\hline TAPSE, $\mathrm{cm}$ & $1.3(1.3-1.5)$ & - & $1.4(1.0-1.5)$ & ns \\
\hline Tricuspid regurgitation (moderate or severe), $n$ & $9(33)$ & - & $8(30)$ & ns \\
\hline Furosemide dosage, mg/day i.v. & $500(125-1,000)$ & $125(0-500)^{*}$ & $60(0-120)^{*}$ & $<0.001$ \\
\hline Fluid balance, $\mathrm{mL} /$ day & $500(0-930)$ & $-1,100(-2,331 \text { to }-500)^{*}$ & $-816(-1,800 \text { to }-387)^{*}$ & $<0.001$ \\
\hline Cumulative urinary output, $\mathrm{mL}$ & $720(480-1,200)$ & $2,329(1,200-3,690)^{*}$ & $2,198(1,666-2,810)^{*}$ & $<0.001$ \\
\hline Lactate, $\mathrm{mmol} / \mathrm{L}$ & $3.3(2.1-6.8)$ & $1.8(1.2-2.2)^{*}$ & $1.5(1.1-2.4)^{*}$ & $<0.001$ \\
\hline Sodium, mmol/L & $133(128-138)$ & $135(131-139)^{*}$ & $137(134-141)^{*}$ & 0.001 \\
\hline Creatinine, $\mu \mathrm{mol} / \mathrm{L}$ & $201(124-296)$ & $180(156-252)$ & $186(131-252)$ & ns \\
\hline Glutamic oxaloacetic transaminase, U/L & $64(32-336)$ & $105(33-605)$ & $84(32-424)$ & ns \\
\hline Glutamic pyruvic transaminase, U/L & $81(24-369)$ & $93(21-871)$ & $87(20-773)$ & ns \\
\hline Bilirubin, $\mu \mathrm{mol} / \mathrm{L}$ & $34(21-52)$ & $24(13-47)$ & $24(13-47)$ & ns \\
\hline
\end{tabular}

Ranges and percentages are given in parentheses. TAPSE, tricuspid annular plane systolic excursion. ${ }^{*}$ p $<0.05$ vs. before IABP.

\section{Statistics}

Continuous variables are reported as medians and interquartile ranges (25-75\%). Categorical variables are described as counts and percentages. Changes among variables at specified times, and differences between IABP responders and non-responders were compared with Wilcoxon matched-pair signed-rank, Friedman 2-way ANOVA, or Mann-Whitney U tests (continuous data, when appropriate) and the Fisher exact tests (categorical data). Cumulative survival was estimated according to the Kaplan-Meier method. Statistical significance of all tests was defined as $\mathrm{p}<0.05$ (two sided). Analyses were performed using the Statistical Package for Social Sciences (version 23; SPSS, Armonk, NY, USA).

\section{Results}

\section{Baseline Characteristics}

Baseline characteristics of the 27 patients are presented in Table 1. All patients were classified as INTERMACS class $1(89 \%)$ or $2(11 \%)$, and $59 \%$ of the patients had biventricular failure. All patients were at high risk according to the HeartMate II risk score $[8,9]$. Eight $(30 \%)$ patients had recurrent ventricular tachycardia.

\section{Effect of IABP Support}

Median duration of IABP support was 4 (3-7) days and the length of intensive care unit (ICU) stay was 14 (7-24) days. During IABP support, mean arterial pressure and central venous oxygen saturation increased (Table 2). Right atrial pressure decreased and urinary output improved, whereas dosages of intravenous furosemide could be reduced. Lactate decreased significantly, while hyponatremia improved. Figure 2 illustrates the clinical outcome of the patients after IABP support. A total of 18 patients $(67 \%)$ had successful IABP treatment and were defined as IABP responders. Of them, 7 patients could be weaned after 4 (3-4) days of support and continued thereafter on medication; 9 patients were supported by IABP for 6 (4-9) days until LVAD or heart transplantation, 1 patient underwent heart transplantation and 1 patient LVAD implantation after IABP removal at 28 and 44 days, respectively. IABP failed in 9 patients $(33 \%)$, defined as non-responders. In this group, 5 patients died during IABP support at 3 (2-9) days, 2 died $<18$ days after removal of IABP due to other organ failure and contraindications to LVAD or transplantation (1 patient had persistent estimated glomerular filtration rate $<30 \mathrm{~mL} /$ min and the other had cardiac AL-amyloidosis secondary to multiple myeloma), and in 2 patients treatment was escalated towards veno-arterial ECMO after 3 and 7 days (these 2 patients underwent later heart transplantation).

\section{Comparison of Clinical and Haemodynamic Parameters}

A comparison of the baseline characteristics between IABP responders and non-responders is presented in $\mathrm{Ta}-$ ble 1 . IABP responders were more frequently female. 


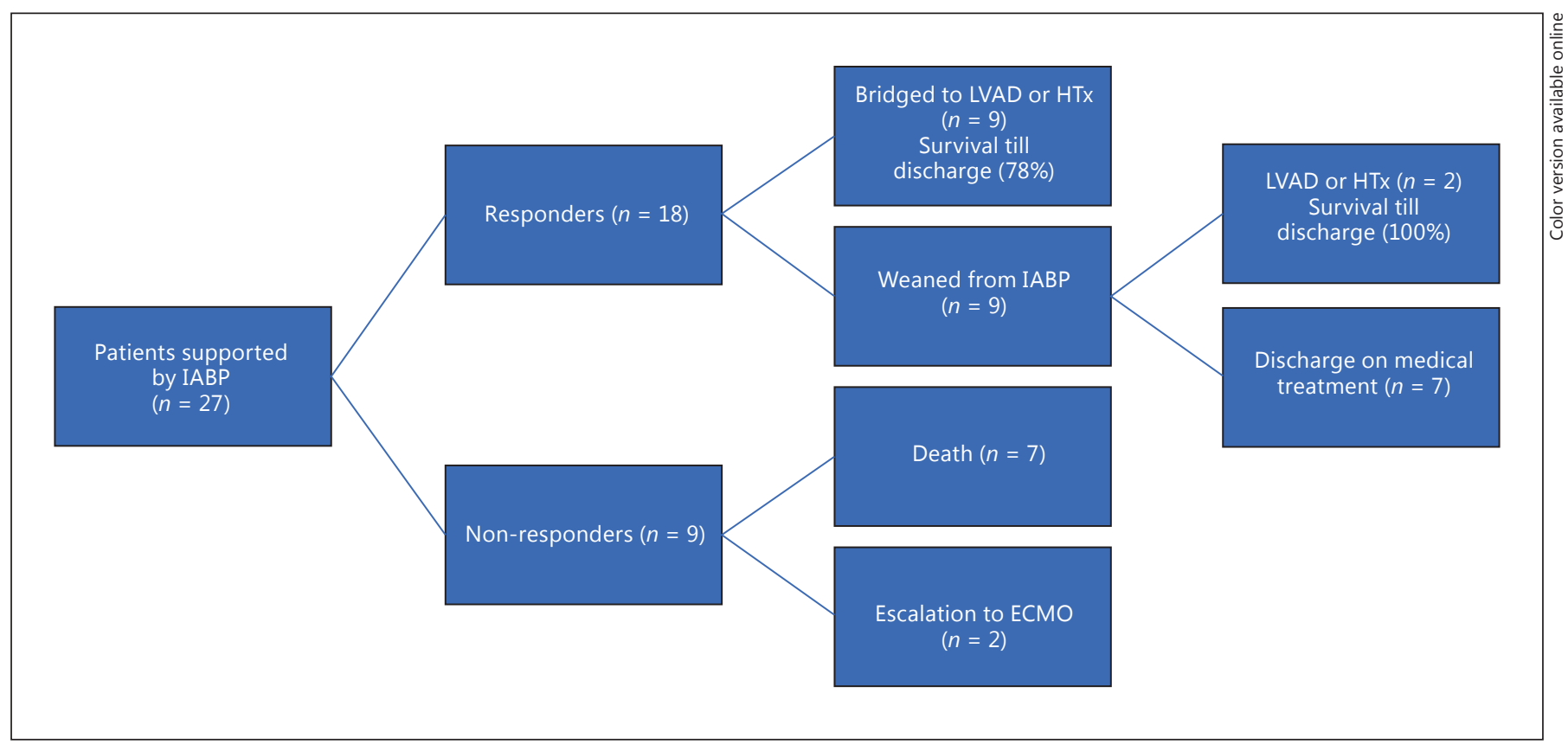

Fig. 2. Flow chart of outcomes. ECMO, extracorporeal membrane oxygenation; HTx, heart transplantation; IABP, intra-aortic balloon pump; LVAD, left ventricular assist device.

Central venous oxygen saturation and LV ejection fraction were lower in non-responders. Baseline serum levels of bilirubin, urea, and C-reactive protein were significantly higher in IABP non-responders than responders.

The clinical changes after IABP insertion in both groups are presented in Figure 3. In IABP responders, mean arterial pressure was higher at $48 \mathrm{~h}$ and CVP was lower at $48 \mathrm{~h}$ than in non-responders. Urinary output was significantly higher at 24 and $48 \mathrm{~h}$ in IABP responders than in non-responders, paralleled by a more negative fluid balance in responders. However, serum creatinine and lactate did not significantly differ between both groups. The duration of support and the length of ICU stay did not differ between responders and non-responders (5 [3-7] vs. 4 [3-11] days and 14 [8-24] vs. 8 [5-19] days, respectively).

\section{Complications and Survival}

Thirty-day mortality was $33 \%$ and tended to be higher in patients with an ischaemic aetiology (3/6: 50\%). Cumulative survival at 1 year was $63 \%$ (Fig. 4). One patient died during IABP support because of a cerebellar haemorrhage in the presence of a cavernous haemangioma. Four patients (15\%) required blood transfusions during IABP support. Two patients developed an access-site hae-

IABP in End-Stage Cardiomyopathy matoma. Positive blood cultures (for Staphylococcus aureus) were present in 1 patient.

\section{Discussion}

In the present study, we show that first-line support by IABP in non-ischaemic CS improves organ perfusion and stabilizes the patient for at least $24 \mathrm{~h}$, as shown by decreased lactate levels in all patients. After $24 \mathrm{~h}$ of IABP support, the patients with urinary output $>2,000 \mathrm{~mL}$ and a negative fluid balance were more likely to be responders who could recover or could be maintained on IABP support until LVAD implantation or heart transplantation.

\section{IABP versus Other Forms of Mechanical Circulatory Support}

IABP has been used since the 1960s, and for a long time it was the only available mechanical device in CS. However, IABP has not improved prognosis in CS complicating AMI $[5,6]$. Refractory low-output heart failure not caused by the acute coronary syndrome represents a subpopulation of CS patients, accounting for less than $10 \%$ of all indications for mechanical circulatory support [7]. Only few reports describe successful use of IABP sup-

Cardiology 2017;138:1-8 DOI: $10.1159 / 000471846$ 


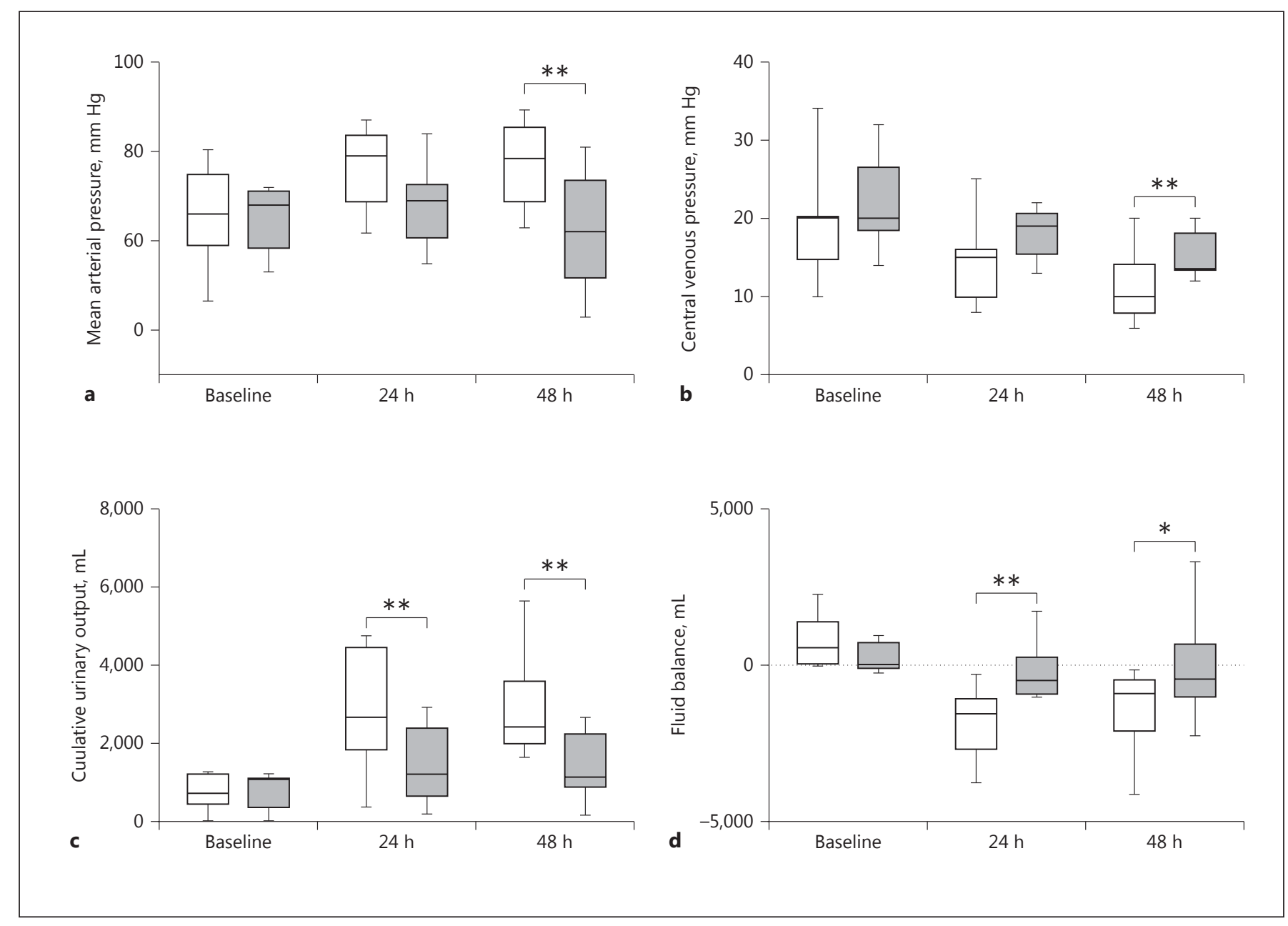

Fig. 3. Box-and-whiskers plots of changes in mean arterial pressure (a), central venous pressure (b), 24-h urinary production (c), and 24-h fluid balance $(\mathbf{d})$. Boxes indicate interquartile ranges and whiskers minimum and maximum values. $\square$, IABP responders; $\square$, IABP non-responders. ${ }^{*} p<0.05,{ }^{* *} p<0.01$.

port as bridge to recovery, LVAD, or transplantation in small groups of patients with NYHA class IV heart failure not related to the acute coronary syndrome deteriorating following CS [10-13]. Although the definitive treatment of refractory heart failure is LVAD implantation or heart transplantation, these complex therapies are associated with increased mortality in INTERMACS class 1 and 2 patients $[14,15]$. On the other hand, it has been shown that the prognosis of patients with severe hypoperfusion bridged to heart transplantation by IABP was similar to that of electively transplanted patients [16]. Thus, stabilisation of patients with short-term circulatory support devices is necessary. This provides time for the selection of suitable candidates and the evaluation of contraindications for advanced mechanical support and transplanta- tion. The level of support is higher by pVAD and ECMO than IABP, but a meta-analysis comparing $\mathrm{PVAD}$ with IABP found no difference in 30-day survival in CS patients [17]. The presence of concomitant RV failure has been associated with early escalation to advanced mechanical circulatory support in patients supported by IABP [18]. The advantages of IABP compared to $\mathrm{pVAD}$ or ECMO consist in a large availability, a reduced complexity of professional training, the possibility of a rapid insertion in the ICU without the need for fluoroscopy, and a low complication rate $[10,19]$.

In our population, IABP support was the last treatment option in 7 patients, who died during support or had major contraindications to heart transplantation or LVAD. Escalation to ECMO was chosen by a multidisci- 
Fig. 4. Kaplan-Meier survival curve of the study population versus patients on intraaortic balloon pump for shock from acute myocardial infarction (AMI) and predicted survival according to the HeartMate II risk score.

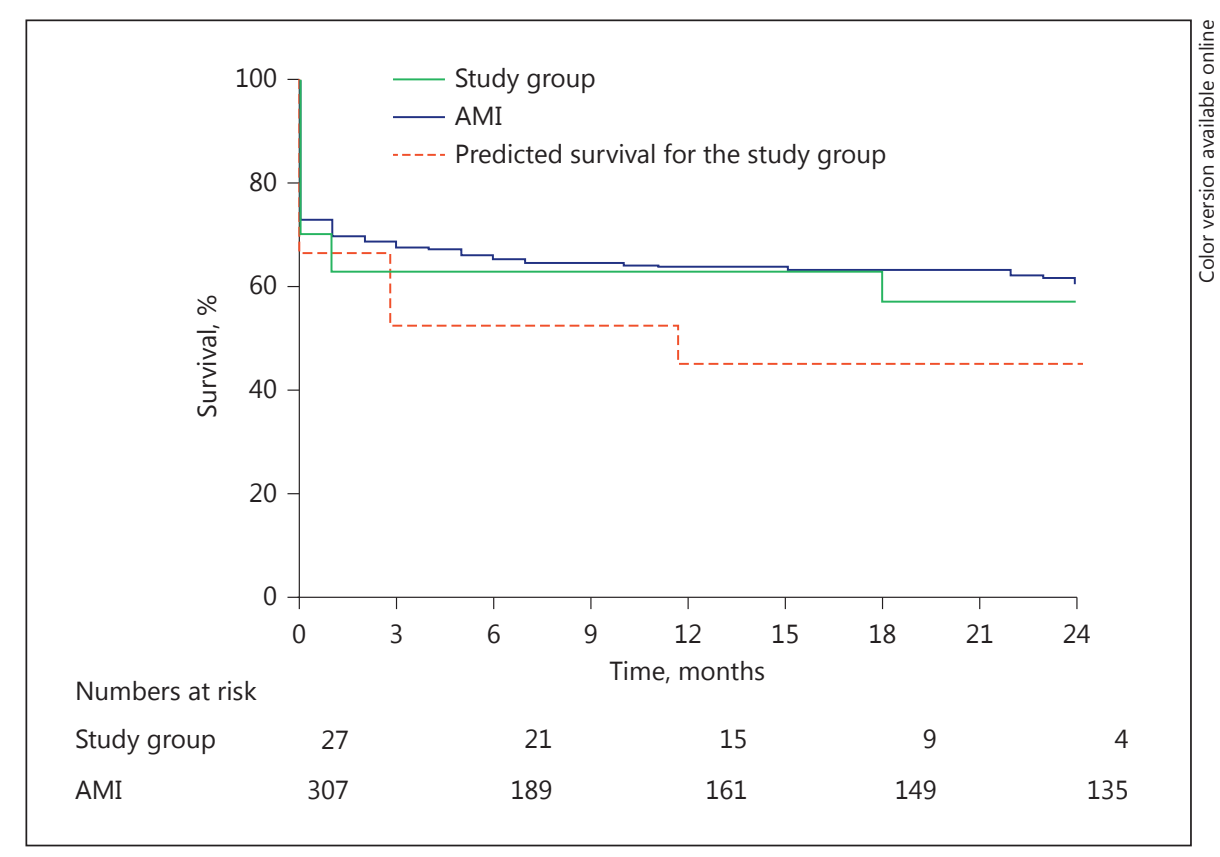

plinary team for 2 patients after 3 and 7 days of IABP support, respectively. These patients underwent later heart transplantation. IABP support remained necessary and provided haemodynamic stability until LVAD implantation or heart transplantation in 9 of our patients, in agreement with other reports [12-14]. However, 9 patients could be weaned from IABP, of which 7 could be discharged on optimal medication and were alive at the 1 -year follow-up. In a previous report, we described our strategy of weaning from mechanic and inotropic support in low-output heart failure patients and reported a high long-term survival in patients able to tolerate $\beta$-blocker therapy at discharge [20].

\section{Monitoring IABP Response}

Elevated blood lactate is an important marker of severe systemic hypoperfusion leading to abnormal cellular oxygen metabolism [21]. At $24 \mathrm{~h}$, we found a significant decrease in lactate levels in the whole cohort, but lactate was not significantly lower in IABP responders than non-responders. On the other hand, higher levels of C-reactive protein and bilirubin baseline values were observed in IABP non-responders than IABP responders, showing that the success of IABP is less likely to occur in the presence of inflammation and multi-organ dysfunction; in these patients, more advanced mechanical support should be considered. Already at $24 \mathrm{~h}$, and persistently at $48 \mathrm{~h}$, the improvement in urinary production with a negative fluid balance was a useful clinical marker of response to treatment, although serum creatinine levels did not significantly improve. This is an interesting clinical observation that received less attention in previous reports about IABP in non-ischaemic CS. One study on ultrasound spectral Doppler estimation of renal flow velocity reported higher renal blood flow during IABP support [22]. Although we did not routinely perform haemodynamic measurements in the present study, we hypothesize that the decrease in LV afterload by IABP increases right to left flow and leads to decreased right-sided congestion and increased renal perfusion, which result in enhanced diuresis.

\section{Survival}

Our study in patients with end-stage non-ischaemic heart failure shows a 1-year survival rate of $63 \%$, which was identical to survival rates stated for patients receiving IABP for CS from AMI. This finding is in line with another retrospective IABP-CS study [10], but in contrast to the TandemHeart-CS study by Kar et al. [23], who reported a better survival in patients with non-ischaemic cardiomyopathy. However, patients categorized as having "non-ischaemic CS" presenting with AMI in the 30 days before study start were excluded in our study, but in fact 6 patients $(22 \%)$ had an ischaemic aetiology and tended to have a worse outcome; therefore, these 6 patients would have been grouped into the ischaemic cardiomyopathy group in the study by Kar et al. [23]. 


\section{Limitations}

The retrospective single-centre design and the small sample size, together with the uncontrolled nature of this study, are important limitations. Haemodynamic invasive measurements were available for 12 of the $27 \mathrm{pa}$ tients. The decisions to wean from IABP support or to escalate to ECMO were based on clinical assessment by a multidisciplinary team and not on predefined criteria. A multivariate analysis of predictors of IABP response could not be performed due to the small size of the cohort, and instead the differences between groups were tested with non-parametric tests.

\section{Conclusion}

This study shows a preserved utility of IABP as firstline mechanical circulatory support in the subpopulation of patients with CS not caused by acute coronary syn- drome and provides practical guidance for the management of these patients. We show that simple clinical parameters, such as mean arterial pressure, central venous pressure, diuresis, and fluid balance can be used to assess response and make decisions about further treatment in the first 24-48 h of IABP support. The low complexity level of IABP management and the low rate of complications enforce the role of IABP as initial circulatory support before resource-intensive devices are employed in non-ischaemic CS.

\section{Disclosure Statement}

None of the authors has a financial relationship with a commercial entity that has an interest in the subject of the presented paper or any other conflict of interest to disclose.

\section{References}

1 Mebazaa A, Tolppanen $\mathrm{H}$, Mueller C, et al: Acute heart failure and cardiogenic shock: a multidisciplinary practical guidance. Intensive Care Med 2016;42:147-163.

2 Ponikowski P, Voors AA, Anker SD, et al: 2016 ESC guidelines for the diagnosis and treatment of acute and chronic heart failure. Rev Esp Cardiol (Engl Ed) 2016;69:1167.

3 Kar B, Basra SS, Shah NR, Loyalka P: Percutaneous circulatory support in cardiogenic shock: interventional bridge to recovery. $\mathrm{Cir}$ culation 2012:125:1809-1817.

4 Santa-Cruz RA, Cohen MG, Ohman EM: Aortic counterpulsation: a review of the hemodynamic effects and indications for use. Catheter Cardiovasc Interv 2006;67:68-77.

5 Thiele H, Zeymer U, Werdan K: Intraaortic balloon support for cardiogenic shock. N Engl J Med 2013;368:81.

6 Thiele H, Zeymer U, Neumann FJ, et al: Intraaortic balloon counterpulsation in acute myocardial infarction complicated by cardiogenic shock (IABP-SHOCK II): final 12 month results of a randomised, open-label trial. Lancet 2013;382:1638-1645.

7 Harjola VP, Lassus J, Sionis A, et al: Clinical picture and risk prediction of short-term mortality in cardiogenic shock. Eur J Heart Fail 2015;17:501-509.

8 Cowger J, Sundareswaran K, Rogers JG, et al: Predicting survival in patients receiving continuous flow left ventricular assist devices: the HeartMate II risk score. J Am Coll Cardiol 2013;61:313-321.

9 Adamo L, Tang Y, Nassif ME, et al: The HeartMate Risk score identifies patients with similar mortality risk across all INTERMACS profiles in a large multicenter analysis. JACC Heart Fail 2016;4:950-958.

10 Lauten P, Rademacher W, Goebel B, et al: Intra-aortic counterpulsation for hemodynamic support in patients with acute ischemic versus non-ischemic heart failure. J Invasive Cardiol 2012;24:583-588.

11 Sintek MA, Gdowski M, Lindman BR, et al: Intra-aortic balloon counterpulsation in patients with chronic heart failure and cardiogenic shock: clinical response and predictors of stabilization. J Card Fail 2015;21:868-876.

12 Norkiene I, Ringaitiene D, Rucinskas K, et al: Intra-aortic balloon counterpulsation in decompensated cardiomyopathy patients: bridge to transplantation or assist device. Interact Cardiovasc Thorac Surg 2007;6:66-70.

13 Gevaert S, Van Belleghem Y, Bouchez S, et al: Acute and critically ill peripartum cardiomyopathy and 'bridge to' therapeutic options: a single center experience with intra-aortic balloon pump, extra corporeal membrane oxygenation and continuous-flow left ventricular assist devices. Crit Care 2011;15:R93.

14 Yusen RD, Edwards LB, Dipchand AI, et al: The Registry of the International Society for Heart and Lung Transplantation: ThirtyThird Adult Lung and Heart-Lung Transplant Report-2016; focus theme: primary diagnostic indications for transplant. J Heart Lung Transplant 2016;35:1170-1184.

15 Kirklin JK, Naftel DC, Pagani FD, et al: Seventh INTERMACS annual report: 15,000 patients and counting. J Heart Lung Transplant 2015;34:1495-1504.

16 Gjesdal O, Gude E, Arora S, et al: Intra-aortic balloon counterpulsation as a bridge to heart transplantation does not impair long-term survival. Eur J Heart Fail 2009;11:709-14.

17 Cheng JM, den Uil CA, Hoeks SE, et al: Percutaneous left ventricular assist devices vs. intra-aortic balloon pump counterpulsation for treatment of cardiogenic shock: a metaanalysis of controlled trials. Eur Heart J 2009, 30:2102-2108.

18 Krishnamoorthy A, DeVore AD, Sun JL, et al: The impact of a failing right heart in patients supported by intra-aortic balloon counterpulsation. Eur Heart J Acute Cardiovasc Care 2016, http://journals.sagepub.com/doi/ abs/10.1177/2048872616652262.

19 Ferguson JJ 3rd, Cohen M, Freedman RJ Jr, et al: The current practice of intra-aortic balloon counterpulsation: results from the Benchmark Registry. J Am Coll Cardiol 2001;38: 1456-1462.

20 Constantinescu AA, Caliskan K, Manintveld OC, van Domburg R, Jewbali L, Balk AH: Weaning from inotropic support and concomitant beta-blocker therapy in severely ill heart failure patients: take the time in order to improve prognosis. Eur J Heart Fail 2014;16: 435-443.

21 Vincent JL, De Backer D: Circulatory shock. N Engl J Med 2013;369:1726-1734.

22 Sloth E, Sprogoe P, Lindskov C, Horlyck A, Solvig J, Jakobsen C: Intra-aortic balloon pumping increases renal blood flow in patients with low left ventricular ejection fraction. Perfusion 2008;23:223-226

23 Kar B, Gregoric ID, Basra SS, Idelchik GM, Loyalka P: The percutaneous ventricular assist device in severe refractory cardiogenic shock. J Am Coll Cardiol 2011;57:688-696. 